\title{
Application of the Multimedia Teaching System Based on Real-time Shooting and Production in Martial Art Course
}

\author{
http://dx.doi.org/10.3991/ijet.v11i03.5347 \\ Yunsong Wang ${ }^{1}$, Aili Qi ${ }^{2}$, Fangfang Cui ${ }^{1}$ \\ ${ }^{1}$ Guizhou Minzu University, Zunyi, China \\ ${ }^{2}$ Guizhou University of Engineering Science, Bijie, China
}

\begin{abstract}
As higher education goes deep continuously, teaching method has become an important research topic of teaching theory in recent years. Multimedia teaching is one of the methods in teaching system. On this basis, this paper develops and designs a multimedia teaching system which can achieve shooting and production at any time, and applies it to teach Martial Art course. Besides, computer technology is applied to design an operable system and construct multimedia teaching system for Martial Art course. Then, by example verification of students in Martial Art class of a college and statistical analysis of data, preliminary trial of multimedia teaching is achieved in practical application. Thus, this paper verifies that multimedia teaching system which can achieve shooting and production at any time can improve teaching quality, and further expounds the function and significance of multimedia teaching method from learning attitude and learning effect.
\end{abstract}

Index Terms-real-time shooting and production, multimedia teaching system, Martial Art

\section{INTRODUCTION}

As society develops continuously, people's living standard improves by a large margin and they turn their attention to spiritual life. In recent years, all kinds of sports meetings have been successfully held so that physical exercise becomes an important content in social life, and starts to be valued in education. But, physical education and management mode in China fall behind, and multimedia and network system are less applied. This gives rise to certain influence on students' learning efficiency, and then affects sports level of the whole country and people's physical quality. The 21 st century is an era of electronic information and network service. Computer technology, multimedia technology and communication information technology have become increasingly mature. This growth further promotes development of multimedia technology and brings new opportunities and challenges for teaching thought and method. Multimedia teaching system can effectively achieve resource sharing. Without space and time limit, students can rationally arrange their time according to their time, learning plan and knowledge structure. Multimedia teaching system which can achieve shooting and production at any time utilizes advanced technology to achieve immediate, real-time and fast release of multimedia information [1].

Aiming at the above problems, both Chinese and overseas research institutions have carried out relevant researches and gained certain achievements. Bañados has created an innovative Communicative English Program using ICT, which is made up of four modules covered in four academic terms. It has been implemented in a blended-learning (b-learning) pedagogical model that includes: (a) Learners' work with UdeC English Online, software conceived as the backbone of the entire Communicative English Program, (b) online monitoring, (c) face-to-face EFL teacher-led classes, and (d) conversation classes with native speakers of English [2]. Wainer and Ingersoll directly implemented intervention study on social competence and communication ability of autistic patients by innovative interactive computer program and virtual reality technology, and obtained good intervention effects [3]. Kern applied multimedia technology in language teaching and got good teaching effects. It has changed language pedagogy and language use, enabling new forms of discourse, new forms of authorship, and new ways to create and participate in communities by Multimedia technology [4]. Yang et al. [5] indicated that effective integration of teaching resource and network multimedia teaching system was an inexorable trend of development on the basis of analyzing college education and teaching environment. Based on cloud platform, Luo and Zhang [6] offered multimedia teaching system, achieved massive media content storage and high-property multimedia content processing, provided user-oriented retrieval customization ability and realized unified resource management. Wang et al. [7] utilized ARM11 processor to study central control system based on multimedia teaching network and achieved multimedia control via wireless network. Su and Huang [8] carried out took virtual multimedia teaching system in modern educational technology for example and researched the application of interactive video, Web interaction and interactive media in experimental course.

With a general survey of scholars' research achievements, it is found that most scholars only implemented independent researches on one aspect and failed to carry out all-round researches. Besides, most research results put particular emphasis on theoretical explanation and lack actual and systematic analysis. In multimedia teaching system, techniques involving real-time shooting and production are very few. Based on existing researches, this paper takes Martial Art course in college physical education. For example, studies implementation and application of real-time shooting and production technology in multimedia teaching system, conducts verification and offers reference value and theoretical support for reform and development of Chinese education reform. This paper contributes to deeply understanding multimedia technology and further developing multimedia technology. 


\section{DEVELOPMENT OF MULTIMEDIA TEACHING SYSTEM BASED ON REAL-TIME SHOOTING AND PRODUCTION}

With continuous development of computer and network environment, diversification trend also appears in multimedia teaching, and practice forms present diversification and deepening $[9,10]$. Multimedia teaching system based on real-time shooting and production is one of the multimedia teaching forms. This teaching system mainly includes camera shooting equipment, information release server and multimedia information release terminator. Traditional multimedia technology stores pictures and videos in some media and releases information via multimedia through certain time and proper processing. Thus, certain time interval and poor instantaneity are caused. Multimedia teaching system based on real-time shooting and production avoids such time interval, shoots and produces pictures and videos as well as effectively releases them. The main feature of this system is that the shooting device transmits pictures or videos shot to information release server in a wireless way so that information release server can utilize multimedia information release terminal to release these pictures or videos. Thus, multimedia information can be released in time. Such system effectively overcomes the problem of time difference.

\section{A. Design of multimedia teaching system based on real- time shooting and production}

Multimedia teaching system based on real-time shooting and production is mainly composed of three parts: shooting device, information release server and multimedia terminal release server, where information release server transmits information to multimedia terminal release server via wireless network and Bluetooth. The structure is shown in Figure 1.

After the information is transmitted to multimedia terminal release server, pictures or videos may be processed. Picture and video processing software is used to adjust the size and format of pictures or videos, clip and merge multiple videos. Finally, according to script structure, Authorwar 7.0 multimedia system editing software is applied to process video materials, load text, picture, sound and video in the document, debug and correct the well-edited procedure. Finally, the document is packed, made into a

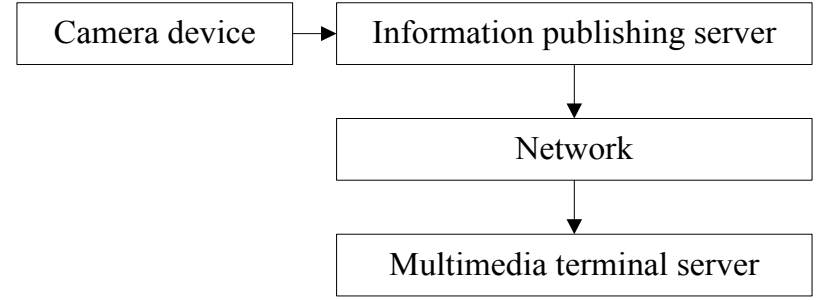

Figure 1. Structure diagram of multimedia information system

disc and uploaded. According to teaching and course features, the structure diagram of the whole content is designed, as shown in Figure 2.

\section{B. Production of multimedia teaching system}

Firstly, main interface is set up. Authorwar7.0 procedure is applied to design the course. For example, the navigation page is mainly divided into five chapters, and a button may be used for switchover and learning exchange. Design procedure interface diagram of main interface is shown in Figure 3. Structure diagram of overall interface of multimedia teaching system is shown in Figure 4. After the procedure operates, the initial effect is presented in the network page. Students may click "pull-down menu" below computer window according to their needs, choose the contents and click to enter the interface of teaching video learning content.

\section{PRACTICE AND APPLICATION OF MULTIMEDIA TEACHING SYSTEM BASED ON REAL-TIME SHOOTING AND PRODUCTION}

\section{A. Object of study}

Among sports speciality classes for which Martial Art course was set in the second semester in a university in 2014, 150 students in Class 1 and Class 2 were selected as the objects of study. 75 students in Class 1 served as the experimental group, and 75 students in Class 2 served as the control group. The teachers teaching Class 1 and Class 2 were same. Baseline survey shows that the difference of students in both groups in learning attitude and Martial Art course examination in the first semester has no statistical significance $(\mathrm{P}>0.05)$, with comparable experimental property.

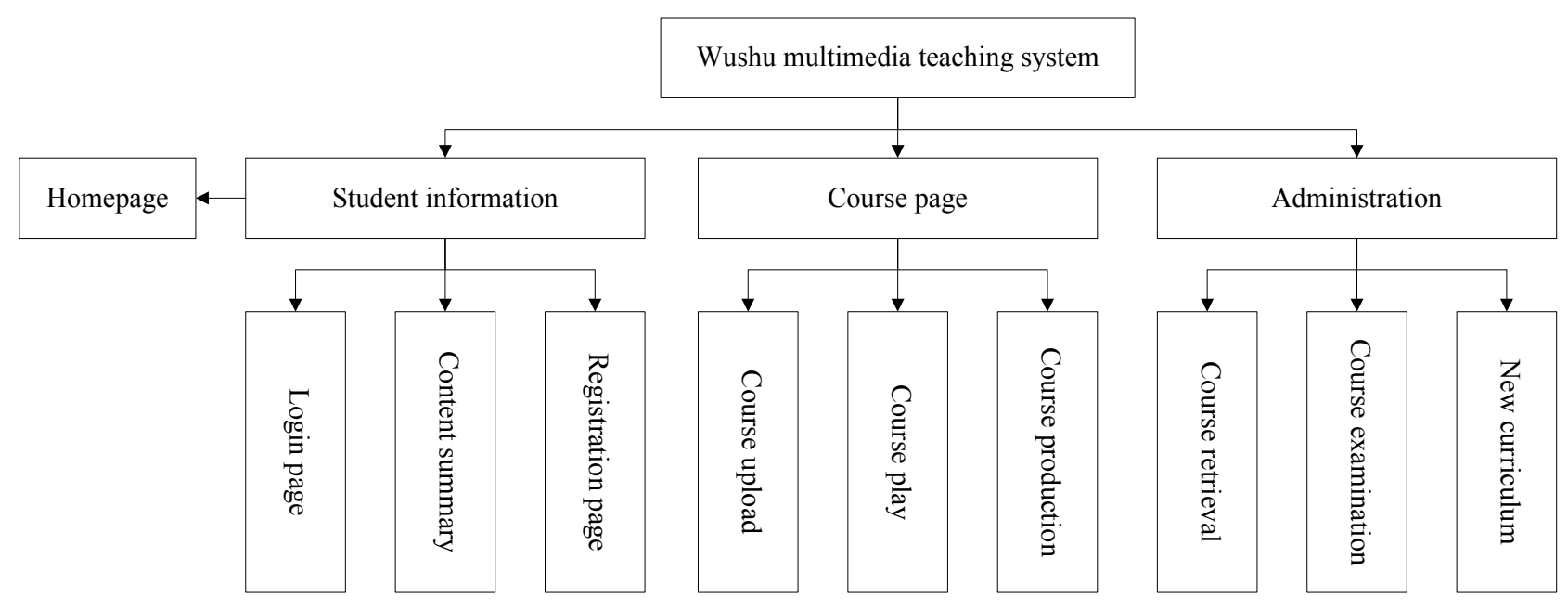

Figure 2. Structure diagram of multimedia teaching system content 


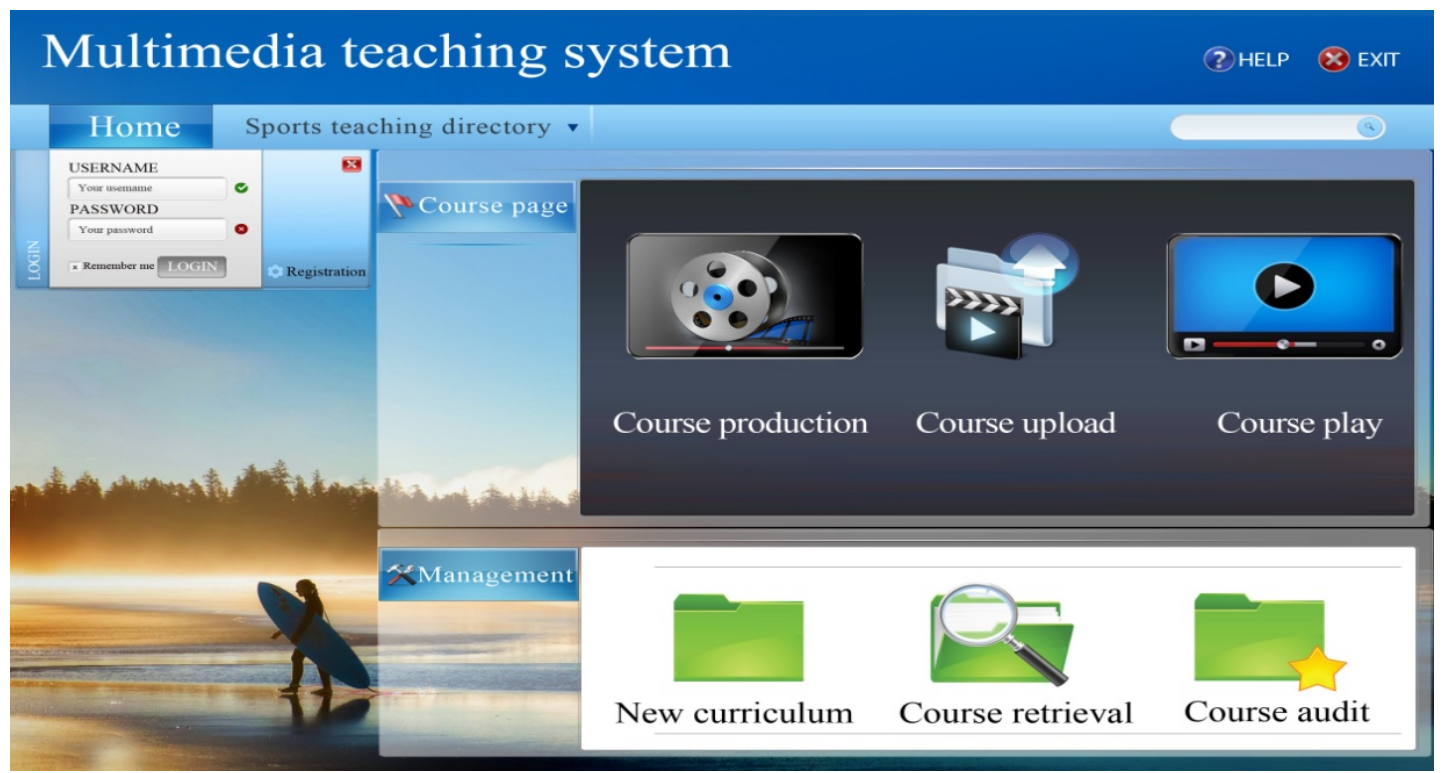

Figure 3. Design interface diagram of multimedia teaching system

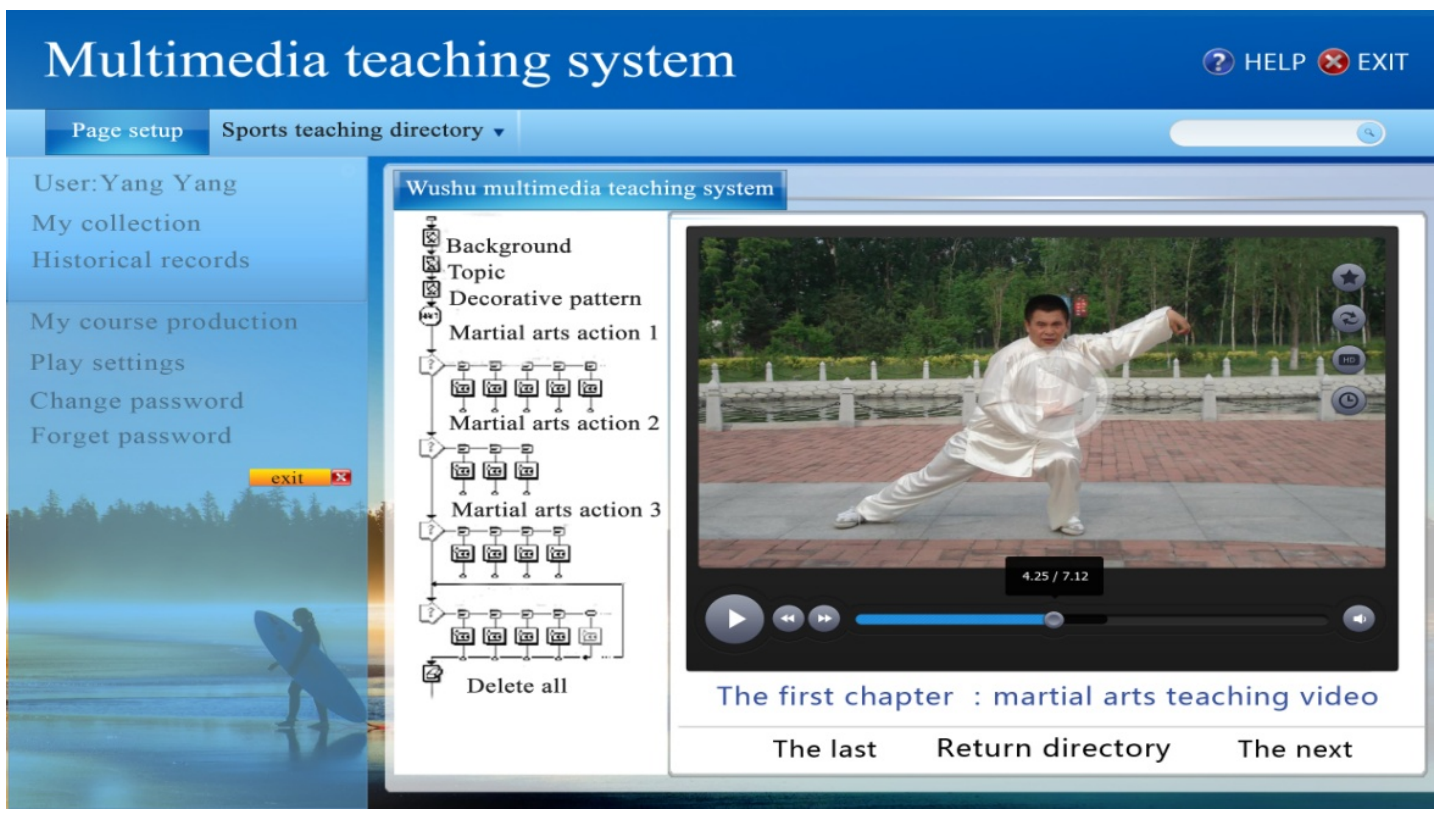

Figure 4. Design interface diagram of multimedia teaching system

\section{B. Research tool}

Self-prepared undergraduate learning attitude questionnaire was used to survey students' learning attitude. This questionnaire consists of 10 items, including the following: (1) The reason for choosing this specialty; (2) love degree for this specialty; (3) cognition of this specialty; (4) view on learning after being admitted to this specialty; (5) current learning diligence degree; (6) whether students can keep up with teachers in class; (7) whether students keep previewing and reviewing; (8) feeling for current learning and living status; (9) purpose of studying; (10) what view they stick to for their future development. Each item contains 4 options from 1 to 4 , expressed with 4 - 1 score, respectively. Questions 2, 5, 6, 7 and 8 are core items about undergraduate learning attitude, while Questions $1,3,4,9$ and 10 are the relatively stable items which are formed in learning attitude and not easily influenced by intervention factor.

\section{Experiment method}

The teaching contents were analyzed, and explicit Martial Art teaching objective was formulated according to the requirements of course outline. The teachers summarized course content, explicitly proposed course objective according to teaching program to let students better learn relevant knowledge of Martial Art in limited classroom. They arranged preview before class, including the chapter to be previewed, knowledge points to be reviewed, teaching class hour arrangement, objective, grouping for study and relevant data to be looked up. Students were promoted to understand the course theory and difficult points through formulating explicit objective and highlighting key points.

Multimedia teaching system and traditional teaching system based on real-time shooting and production was utilized to guide students for independent study and to carry out contrastive analysis. The methods include the 
following: written examination in middle semester and at the end of the semester, and basic knowledge mastery; students' communication in class, problems, solutions and harvest in exchange and learning process; performance and practice of Martial Art course, such as action imitation and exercise; exercise in pair and check whether the learning process and action skills comply with actual requirements of Martial Art study; read and comment on exercise report, practice report and assignments, and give proper feedbacks.

The effect of multimedia teaching system based on realtime shooting and production was conducted. Learning effect evaluation is an important stage of teaching system function inspection. The assessment process was achieved through assessing students' course result, evaluating and summarizing their learning attitude.

\section{Data processing}

Epidata 3.1 software was applied to carry out doublepeople and double-data entry. After the data were checked, SPSS 16.0 data software was used for data analysis. Statistical methods adopted include Willcxon rank sum test and independent-samples $\mathrm{T}$ test. $\mathrm{P}<0.05$ means the difference has statistical significance.

\section{E. Research results}

150 questionnaires were distributed in total, and all questionnaires were recovered. 8 unqualified questionnaires were eliminated. Finally 142 effective questionnaires were gained, including 72 questionnaires from the experimental class, and 70 questionnaires from the control class. Learning attitude of students in two groups before and after the learning method was applied was compared. Willcxon rank sum test was adopted to gain students' learning attitude comparison for multimedia teaching method based on real-time shooting and production in Martial Art Course, as shown in Table 1.

According to Table 1, the students in both classes show statistical significance in Question 5 (students' learning diligence degree) and Question 6 (students' understanding of teaching content and interest). In other words, by use of multimedia teaching system based on real-time shooting and production, students are more interested in learning Martial Art and their attitude is also relatively close to multimedia teaching. Besides, they can understand the teaching contents more easily and deeply cognize specific actions of martial art.

Moreover, the average score of experimental class at the end of the semester is $80.14 \pm 6.87$, while the average score of control class at the end of the semester is 75.69 \pm 9.25 . The result of independent-samples $T$ test indicates the difference owns statistical significance $(\mathrm{t}=3.261, \mathrm{P}=0.001)$. This means multimedia teaching system based on real-time shooting and production owns good teaching effect.

\section{F. Analysis of research results}

The science of Martial Art is a typical sports discipline, with profound theory, complex mechanism and a wide range of action knowledge. Thus, the science of Martial Art has complicated knowledge and practice structure. As sports learning degree deepens, relevant course teaching contents and sports degree also increase. For students it is not easy to understand relevant concepts in study and cannot fully practice the actions. Thus, crossed connection of actions may occur. In addition, martial art requires certain physical quality and needs to make students give full play to thinking ability and body action mechanism. Hence, to learn Martial Art course well, students must exercise more, communicate, keep up with teachers and exercise over and over again after class. Multimedia teaching system based on real-time shooting and production can effectively overcome time and space limit and reach the purpose of learning anytime and anywhere. Therefore, such teaching system is of great significance.

Multimedia teaching method boosts professional quality requirements for students. Compared with traditional teaching methods, multimedia teaching method not merely requires teachers to own good teaching skills and classroom control ability, but also requires them to well grasp teaching contents and knowledge structure, and fully display them in course teaching. Meanwhile, teachers should let students comprehend by analogy, connect the knowledge, and fully know course content through video, text and sound so as to motivate their learning interest.

Multimedia teaching method based on real-time shooting and production improves the requirement for teaching conditions. It is required to combine actual practice and multimedia technology, shoot and provide relevant courseware video, perfect knowledge content. Therefore, superior and all-round teaching conditions are needed.

Multimedia teaching method based on real-time shooting and production enhances the requirement for students' learning. Traditional Martial Art teaching mode is such that the teacher provides a site for study. Multimedia teaching breaks time and space limit so that students can learn in an appropriate site according to their time. However, without teacher's supervision, students need own good self-discipline, which enhances students' sense of urgency. Besides, students need to prepare for the course well.

TABLE I. COMPARISON RESULTS OF LEARNING ATTITUDE OF STUDENTS IN BOTH CLASSES TO SUCH MULTIMEDIA TEACHING METHOD

\begin{tabular}{c|l|c|c|c|c|c|}
\hline Question & \multicolumn{1}{|c|}{ Group } & Before teaching & After teaching & D-value & Intra-group comparison P & D-value comparison P \\
\hline 2 & Experimental class & $2.75 \pm 0.45$ & $2.85 \pm 0.42$ & $0.10 \pm 0.19$ & 0.173 \\
\hline & Control class & $2.74 \pm 0.47$ & $2.79 \pm 0.41$ & $0.05 \pm 0.18$ & 0.501 \\
\hline 5 & Experimental class & $2.54 \pm 0.37$ & $2.75 \pm 0.44$ & $0.21 \pm 0.15$ & 0.002 \\
\hline & Control class & $2.49 \pm 0.42$ & $2.62 \pm 0.48$ & $0.13 \pm 0.19$ & 0.088 \\
\hline 6 & Experimental class & $2.15 \pm 0.37$ & $2.45 \pm 0.37$ & $0.30 \pm 0.21$ & 0.000 \\
\hline 7 & Control class & $2.21 \pm 0.35$ & $2.35 \pm 0.41$ & $0.14 \pm 0.22$ & 0.030 \\
\hline & Experimental class & $2.25 \pm 0.45$ & $2.29 \pm 0.45$ & $0.04 \pm 0.13$ & 0.597 & 0.893 \\
\hline & Control class & $2.31 \pm 0.45$ & $2.32 \pm 0.43$ & $0.01 \pm 0.14$ & 0.110 \\
\hline & Experimental class & $2.85 \pm 0.52$ & $2.97 \pm 0.49$ & $0.12 \pm 0.21$ & 0.159 \\
\hline
\end{tabular}




\section{CONCLUSIONS}

Multimedia teaching system based on real-time shooting and production alters traditional teaching mode and creates a new student-based teaching mode in which the teacher serves as a guide and video is used for learning. As social development make great progress, sports learning receives more and more attention. The society needs comprehensive talents who can combine theoretical knowledge with practical skill and ability. The ultimate purpose of multimedia teaching is to change traditional teaching mode and cultivate qualified talents who are suitable for requirements of the new age. Multimedia teaching mode based on real-time shooting and production can well solve the defects of traditional teaching method. It helps to overcome time and space control, utilize internet technology to reach the purpose of online learning and practice anytime and anywhere. Hence, students can learn knowledge repeatedly and independently. Multimedia teaching mode better complies with the reform of modern education. Computer development offers convenient teaching conditions for multimedia teaching. This research to some extent offers some new thoughts for other analysis methods and contributes to improving teaching quality. But, many problems are still faced from theory to practice, and teaching reform system is not sound. Furthermore, such teaching mode puts forward higher requirements for teachers, students and teaching conditions. For the teachers and students who have been accustomed to traditional teaching mode, such teaching mode is a great challenge. In one word, the development of multimedia teaching system needs long-term efforts.

\section{SugGeStions}

In combination of practical teaching of Martial Art speciality and actual conditions, this paper recommends the following suggestions for application of multimedia teaching method based on real-time shooting and production. Firstly, it is necessary to enhance investment in teaching facilities and offer basic conditions, the application of this method cannot be separated from advanced facilities and technology. Thus, colleges should develop and use advanced shooting device, information release system and transmission system. Secondly, colleges should optimize learning environment and create favorable atmosphere for students. Thirdly, teachers should pay attention to course teaching diversification and individuation, boost teaching quality, cultivate students' learning interest and lay a foundation for sustainable development of multimedia teaching system.

\section{REFERENCES}

[1] Malik S., Agarwal A., "Use of multimedia as a new educational technology tool-a study," International Journal of Information and Education Technology, vol. 2, no. 5, pp. 468-471, October 2012. http://dx.doi.org/10.7763/IJIET.2012.V2.181

[2] Bañados E., "A blended-learning pedagogical model for teaching and learning EFL successfully through an online interactive multimedia environment," Calico Journal, vol. 23, no. 3, pp. 533-550, October 2013.

[3] Wainer A.L., Ingersoll B.R., "The use of innovative computer technology for teaching social communication to individuals with autism spectrum disorders," Research in Autism Spectrum Disorders, vol. 5, no. 1, pp. 96-107, January-March 2011. http://dx.doi.org/10.1016/j.rasd.2010.08.002

[4] Kern R., "Perspectives on technology in learning and teaching languages," Tesol Quarterly, vol. 40, no. 1, pp. 183-210, March 2006. http://dx.doi.org/10.2307/40264516

[5] Yang L.H., Zhou F., Ren Y.J., "On network multimedia teaching system and teaching resource integration," Journal of Qujing Normal University, vol. 27, no. 3, pp. 147-148, March 2008.

[6] Luo W., Zhang G.B., "Research and design of multimedia teaching system based on cloud platform," Electronic Technology, vol. 37 , no. 22, pp. 47-50, November 2013.

[7] Wang Y.G., Wang S, Zhao HZ., "Design of central control system of multimedia teaching network based on ARM11 processor," Electronic Technology and Software Engineering, no. 19, pp. 7172, October 2014.

[8] Su Y.N., Huang Y.L., "Flipped classroom mode design and application based on interactive experimental simulation software case study of virtual multimedia teaching system," China Educational Technology, no. 10, pp. 60-67, October 2015.

[9] Parks S., Huot D., Hamers J., Lemonnier F.H., "Crossing boundaries: Multimedia technology and pedagogical innovation in a high school class," Language Learning \& Technology, vol. 7, no. 1, pp. 28-45. January 2003.

[10] Chen C.H., She H.C., "The Impact of Recurrent On-line Synchronous Scientific Argumentation on Students' Argumentation and Conceptual Change," Journal of Educational Technology \& Society, vol. 15, no. 1, pp. 197-210, January 2012.

\section{AUTHORS}

Yunsong Wang (Corresponding author) is an Associate Professor in Guizhou Minzu University, Zunyi 550025, China. His research interests include physical education and offline education (wangyunsong22@yeah.net).

Aili Qi is an Associate Professor in Guizhou University of Engineering Science, Bijie 551700, China. Her research interests include sports psychology and offline education (qiailili@yeah.net).

Fangfang Cui is a postgraduate in Guizhou University of Engineering Science, Bijie 551700, China. Her research interests include sports psychology and offline education (yingyuyingpin2012@163.com).

This work was supported by College of Humanities and Social Sciences Research Projects of Guizhou Provincial Education Department [14QN064], College of Humanities and Social Sciences Research Projects of Guizhou Provincial Education Department [2015DXS29], Guizhou Provincial Education Science Plan Project [2013B123]. Submitted 10 December 2015. Published as resubmitted by the authors 24 February 2016. 